\title{
Pharmacokinetics of Glutathione-Dextran Macromolecular Conjugate in Mice
}

\author{
Yoshiharu Kaneo,* Tomochika Uemura, Tetsuro Tanaka, Satoshi Kanoh, and \\ Aya MATSUOKA
}

Department of Biopharmaceutics, School of Pharmacy, Fukuyama University, Sanzo, Gakuen-cho, Fukuyama, Hiroshima, 729-02, Japan. Received April 10, 1995; accepted July 25, 1995

\begin{abstract}
A fluorescein-labeled dextran-glutathione conjugate (FD-GSH) was synthesized in order to examine its disposition in the body. GSH was covalently attached to the FITC-labeled dextran by the cyanogen bromide activation method. Mice were injected with FD-GSH through the tail vein, and the levels of FD-GSH in the blood and various organs were measured fluorometrically. A substantial level of FD-GSH was found in the liver and this reached a maximum at $6-8 \mathrm{~h}$ after the injection. The hepatic uptake clearance was estimated to be $0.541 \pm 0.014 \mathrm{ml} / \mathrm{h} / \mathrm{g}$ tissue or $42.4 \pm 9.8 \mathrm{ml} / \mathrm{h} / \mathrm{kg}$ body weight. FD-GSH accumulated in the liver for a long period, while the half-life of the conjugate in the blood circulation was $1.45 \mathrm{~h}$. The cumulative urinary and fecal excretions of FD-GSH were $14 \%$ and $4 \%$ of dose at $72 \mathrm{~h}$ after the injection, respectively. A molecular design of the conjugate was discussed on the basis of the results.
\end{abstract}

Key words glutathione; dextran; conjugate; fluorescein; cyanogen bromide; pharmacokinetics; mouse

Tripeptide glutathione (GSH), a naturally occurring antidote, cannot permeate into the liver when given extracellularly, ${ }^{1}$ and has a very short half-life in the circulation due to its rapid renal degradation. ${ }^{2-4)} \mathrm{A}$ dextran conjugate of GSH was synthesized by coupling GSH covalently to dextran by the $\mathrm{CNBr}$ activation method in order to overcome these disadvantages. ${ }^{5)}$ We have demonstrated that GSH is delivered effectively into the hepatic cells by the conjugate which protects mice from acetaminophen hepatotoxicity. ${ }^{6-8)}$

Dextrans are clinically acceptable polysaccharides of linear chains of $\alpha$-D-glucose molecules; $95 \%$ of the chains consist of $\alpha 1,6$-linked linear glucose units while the side chains consist of $\alpha 1,3$-linked moieties. ${ }^{9)}$ It has been suggested that the kinetic behavior of the dextran-drug conjugates is governed primarily by the kinetics of their dextran carriers. ${ }^{10)}$ In a previous work, it was suggested that molecular size is one of the most critical factors in the delivery of GSH, as a dextran conjugate, into the liver, based on a comparison of the prophylactic effect on the acetaminophen-induced hepatotoxicity. ${ }^{11)}$

In this study, we synthesized a fluorescein-labeled dextran-GSH conjugate, and examined its disposition in the body of mice.

\section{MATERIALS AND METHODS}

Chemicals Dextran $(\mathrm{T}-40, \mathrm{MW}=43900)$ was purchased from Pharmacia Fine Chemical Co., Sweden. GSH and fluorescein isothiocyanate isomer I (FITC) were obtained from Sigma Co., U.S.A. and Dojindo Laboratories, Kumamoto, Japan, respectively. All other chemicals and reagents were of the highest grade commercially available.

Preparation of FITC-Labeled Dextran-GSH Conjugate (FD-GSH) FITC-labeled dextran was prepared by the method of de Belder and Granath. ${ }^{12)}$ Dextran $(1 \mathrm{~g})$ was dissolved in methyl sulphoxide $(10 \mathrm{ml})$ containing a few drops of pyridine. FITC was added, followed by dibutyltin dilaurate $(20 \mathrm{mg})$, and the mixture was heated for $2 \mathrm{~h}$ at

* To whom correspondence should be addressed. $95^{\circ} \mathrm{C}$. After several precipitations in ethanol to remove free dye, the FITC-dextran was filtered off and dried in vacuo at $80^{\circ} \mathrm{C}$. The FITC-dextran was further purified by size-exclusion chromatography on Sephadex G-25, and then freeze-dried.

GSH was covalently attached to the FITC-dextran by the cyanogen bromide activation method. ${ }^{5,13)}$ To a stirred solution of the FITC-dextran $(0.2 \mathrm{~g})$ in water $(20 \mathrm{ml}) \mathrm{CNBr}$ was added in three portions $(40,40,30 \mathrm{mg})$. The $\mathrm{pH}$ was maintained between 10.7 and 11.0 during this process by addition of $4 \mathrm{M} \mathrm{NaOH}$. Six min after the final addition of $\mathrm{CNBr}$, the $\mathrm{pH}$ was adjusted to 6.5 by addition of $0.1 \mathrm{M}$ $\mathrm{HCl}$. Then, GSH $(0.4 \mathrm{~g})$ was added maintaining the $\mathrm{pH}$ at 6.5 and the coupling reaction was allowed to proceed for $18 \mathrm{~h}$ at $4{ }^{\circ} \mathrm{C}$. The reaction mixture was washed repeatedly with $0.1 \mathrm{M} \mathrm{CH}_{3} \mathrm{COOH}$ by pressure dialysis using a Toyo HP-43 ultrafiltration cell incorporating a UP-20 membrane (Toyo, Tokyo, Japan) and finally concentrated to a volume of $10 \mathrm{ml}$. Excess reagents and low molecular by-products of the reaction were removed by this process. The product, a FD-GSH, was obtained by lyophilization of the final solution.

Analytical Method The degree of the binding of GSH to the FITC-dextran was estimated by measuring the sulfhydryl groups of FD-GSH. ${ }^{14)}$ The amount of FDGSH in biological samples was determined fluorometrically. The tissue homogenate or urine $(40 \mu \mathrm{l})$ was added to $3 \mathrm{ml}$ of a $0.5 \mathrm{M}$ Tris- $\mathrm{HCl}$ buffer ( $\mathrm{pH} 8.0$ ) containing $0.1 \%$ of sodium dodecylsulfate. After thorough mixing, fluorescence at $520 \mathrm{~nm}$ was determined with the activation at $495 \mathrm{~nm}$. The blood space of each organ was determined by the tissue distribution data of FITC-labeled dextran (T-70; $\mathrm{MW}=74300$ ) at $2 \mathrm{~min}$ after intravenous injection $(120 \mathrm{mg} / \mathrm{kg})$. This value was used to correct for the presence of drug in the residual blood remaining in the organ.

Animal Experiment Male ddy mice $(20-30 \mathrm{~g})$ were obtained from the Shizuoka Agricultural Cooperative Association for Laboratory Animals (Shizuoka, Japan). Mice were injected with FD-GSH $(120 \mathrm{mg} / \mathrm{kg})$ in $0.2 \mathrm{ml}$

(C) 1995 Pharmaceutical Society of Japan 
of saline through the tail vein. At $0.5,1,2,4,6,8,12$ and $24 \mathrm{~h}$ after the administration, blood was collected from the vena cava under ether anesthesia and various organs (liver, kidney, lung, spleen, brain, and gallbladder) were excised and weighed. Liver samples were further collected at 2, 3, 5, 10,20 and $30 \mathrm{~d}$ after the drug administration. Each organ was homogenized using a 19-fold volume of $0.1 \mathrm{M}$ phosphate buffer ( $\mathrm{pH}$ 7.4). For gallbladder, a 119fold volume of the buffer was used to make a homogenate.

Urine and feces samples were collected for $72 \mathrm{~h}$ after the administration of FD-GSH. Feces were homogenized using 19-fold volume of the buffer. The homogenate was centrifuged at $2500 \mathrm{rpm}$ and the supernatant was filtered.

All samples of the organ homogenates, the feces filtrate and the urine were kept frozen at $-20^{\circ} \mathrm{C}$ until analyzed.

Data Analysis Assuming the efflux of FD-GSH from the liver is negligible during the time studied, the hepatic uptake clearance $\left(C L_{\mathrm{h}}\right)$ can be described as follows ${ }^{15)}$ :

$$
C L_{\mathrm{h}}=H\left(t_{1}\right) / A U C_{0 \rightarrow t_{1}}
$$

where $H\left(t_{1}\right)$ is the hepatic level of FD-GSH at time $t_{1}$ and $A U C_{0 \rightarrow t_{1}}$ is the area under the blood concentration-time curve up to that time.

The total clearance $\left(C L_{\mathrm{tot}}\right)$ and the renal clearance $\left(C L_{\mathrm{r}}\right)$ of FD-GSH were calculated by the following equations:

$$
\begin{aligned}
& C L_{\mathrm{tot}}=D / A U C_{0 \rightarrow \infty} \\
& C L_{\mathrm{r}}=\left(X_{\mathrm{u}}\right)_{\infty} / A U C_{0 \rightarrow \infty}
\end{aligned}
$$

where $D$ and $\left(X_{\mathrm{u}}\right)_{\infty}$ are the dose of FD-GSH and the total amount of FD-GSH excreted into the urine, respectively. $A U C_{0 \rightarrow \infty}$ is the $A U C$ up to infinity.

\section{RESULTS}

The conjugate (FD-GSH) was a water-soluble yellow powder containing $4.9 \%(\mathrm{w} / \mathrm{w})$ of $\mathrm{GSH}$ according to the determination of sulfhydryl group by the method of Ellman. The degrees of substitution by GSH and by FITC of dextran were estimated to be one molecule per approximately 35 and 400 glucose units, respectively. In all cases the conjugate was completely soluble in water.

Figure 1 shows the tissue distribution of FD-GSH after intravenous injection of the conjugate. A substantial level of FD-GSH was found in the liver and it reached a maximum at $6-8 \mathrm{~h}$ after the injection. Allowing for the weight of the liver, the total amount of FD-GSH recovered in this organ at $8 \mathrm{~h}$ after the injection was $38 \%$ of dose.

The blood concentration-time curve of FD-GSH after intravenous injection of the conjugate is shown in Fig. 2. The conjugate exhibited a monoexponential decline; the calculated half-life and volume of distribution were $1.45 \mathrm{~h}$ and $180 \mathrm{ml} / \mathrm{kg}$ body weight (Table 1).

The time profiles of cumulative urinary and fecal excretions of FD-GSH are depicted in Fig. 3. The urinary excretion terminated within $12 \mathrm{~h}$ and $14 \%$ of dose was excreted totally in urine. The amount of FD-GSH excreted in feces was $4 \%$ of dose at $72 \mathrm{~h}$ after the injection, but continued to increase gradually.

Figure 4 shows that FD-GSH was appreciably distributed in the liver and accumulated there over a long period.

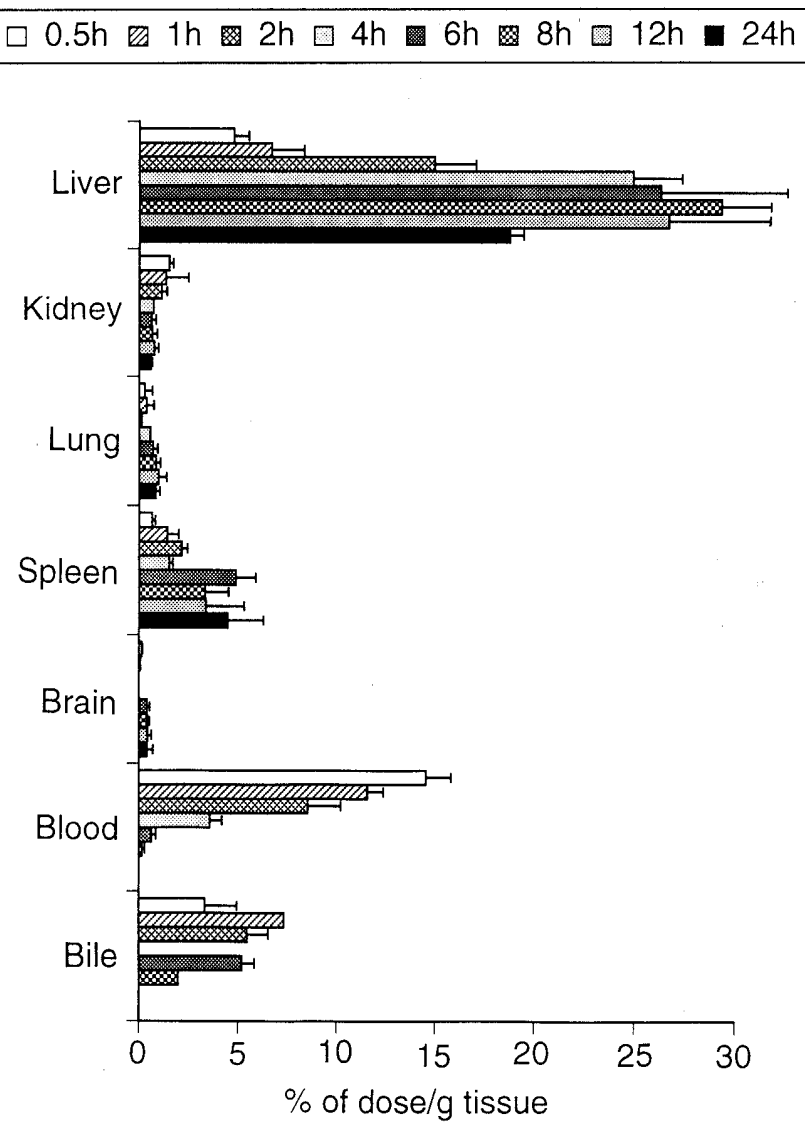

Fig. 1. Tissue Distribution of FD-GSH in Mice after Intravenous Injection $(120 \mathrm{mg} / \mathrm{kg})$

Values are given as means \pm S.D. for groups of 3 mice.

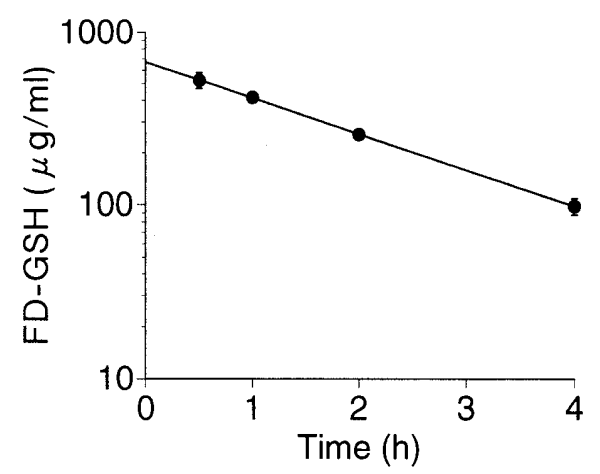

Fig. 2. Blood Level of FD-GSH in Mice after Intravenous Injection $(120 \mathrm{mg} / \mathrm{kg})$

Values are given as means \pm S.D. for groups of 3 mice.

Table 1. Pharmacokinetic Parameters of FD-GSH in Mice after Intravenous Injection $(120 \mathrm{mg} / \mathrm{kg})$

\begin{tabular}{lc}
\hline Elimination rate constant $\left(\mathrm{h}^{-1}\right)$ & $0.478 \pm 0.004$ \\
Biological half-life $(\mathrm{h})$ & $1.45 \pm 0.01$ \\
Volume of distribution (ml/kg body weight) & $180 \pm 1$ \\
Total clearance $(\mathrm{ml} / \mathrm{h} / \mathrm{kg}$ body weight) & $86.0 \pm 0.9$ \\
Hepatic clearance & \\
$\quad(\mathrm{ml} / \mathrm{h} / \mathrm{g}$ tissue) & $0.541 \pm 0.014$ \\
$(\mathrm{ml} / \mathrm{h} / \mathrm{kg}$ body weight) & $42.4 \pm 9.8^{a)}$ \\
Renal clearance $(\mathrm{ml} / \mathrm{h} / \mathrm{kg}$ body weight) & $12.1 \pm 2.5^{b)}$ \\
Mean residence time in blood (h) & 1.70 \\
Mean residence time in liver $(\mathrm{d})$ & 12.2
\end{tabular}

a) The ratio of the liver weight to the body weight was $0.0783 \pm 0.018$ in mice of the average body weight of $24.3 \pm 2.9 \mathrm{~g}(n=41)$. b) Total urinary excretion of FD-GSH was $14.1 \pm 2.9 \%$ of the dose. 


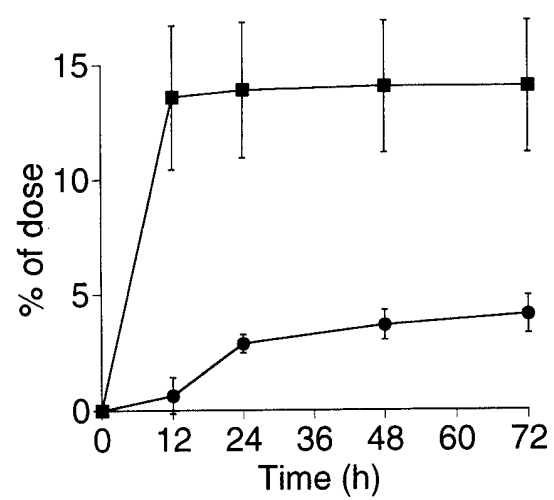

Fig. 3. Cumulative Urinary ( $(\boldsymbol{)})$ and Fecal ( ) Excretions of FD-GSH in Mice after Intravenous Injection $(120 \mathrm{mg} / \mathrm{kg})$

Values are given as means \pm S.D. for groups of 3 mice.

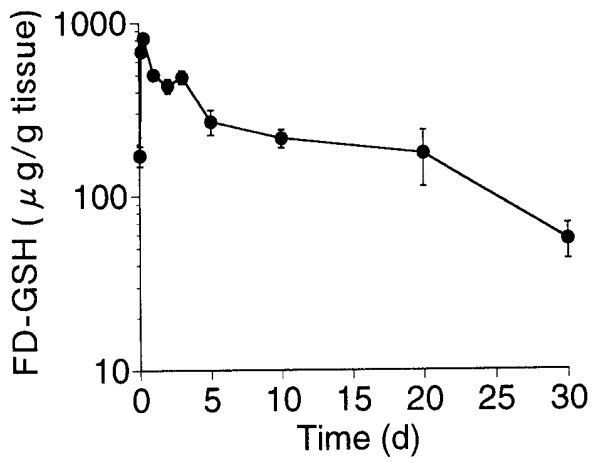

Fig. 4. Hepatic Level of FD-GSH in Mice after Intravenous Injection $(120 \mathrm{mg} / \mathrm{kg})$

Values are given as means \pm S.D. for groups of 3 mice.

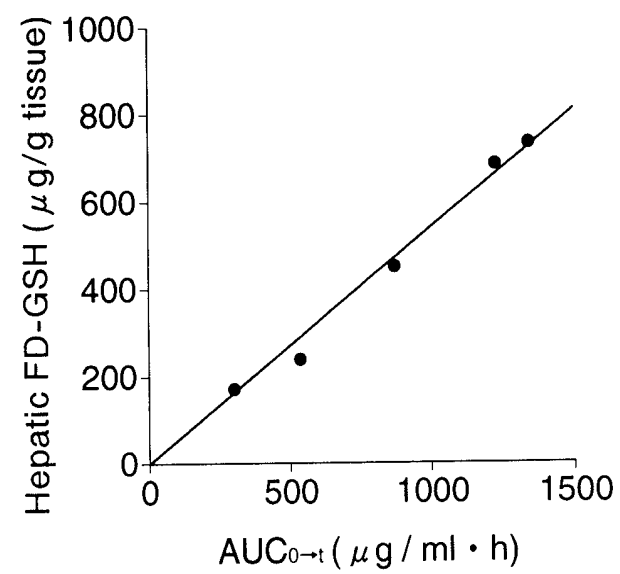

Fig. 5. Relationship between Hepatic FD-GSH in Mice at Time $t$ and $A U C_{0 \rightarrow 1}$ after Intravenous Injection $(120 \mathrm{mg} / \mathrm{kg})$

At $30 \mathrm{~d}$ after the injection of FD-GSH, $4.8 \%$ of dose $(56 \mu \mathrm{g} / \mathrm{g}$ tissue) was still detectable in this organ. The hepatic mean residence time was $12 \mathrm{~d}$ (Table 1 ).

The integration plot, that is, the relationship between hepatic level of FD-GSH at time $t$ and $A U C_{0 \rightarrow t}$ after intravenous injection in mice, was plotted as shown in Fig. 5. The slope of the linear regression line gave the hepatic uptake clearance, which was estimated to be $0.541 \pm$ $0.014 \mathrm{ml} / \mathrm{h} / \mathrm{g}$ tissue or $42.4 \pm 9.8 \mathrm{ml} / \mathrm{h} / \mathrm{kg}$ body weight (Table 1).

\section{DISCUSSION}

GSH was covalently attached to FITC-labeled dextran by the $\mathrm{CNBr}$ activation method. ${ }^{13)}$ The isoelectric point of the conjugate was estimated to be 2.5 by cellulose acetate paper electrophoresis. ${ }^{5)}$ This was due to the attachment of GSH, which has two carboxyl groups ( $\mathrm{p} K_{\mathrm{COOH}(1)}=2.12$, $\left.\mathrm{p} K_{\mathrm{COOH}(2)}=3.53\right)$ and shows relatively high acidity $(\mathrm{pH}$ $1-2$ ) in aqueous solution.

The size exclusion chromatography of FD-GSH was done on a Sephadex G-150 column. The conjugate eluted earlier than the original dextran and the elution peak tended to be broadened to some extent. The molecular weight corresponding to the peak estimated by interpolation of the calibration curve of the dextran standards was $250 \mathrm{kD}$. Attachment of GSH to dextran $(4.9 \%(\mathrm{w} / \mathrm{w}))$ did not explain the marked increase in the molecular weight of the conjugate. The authors' previous work ${ }^{5)}$ indicated that at least $80 \%$ of the conjugated GSH is attached to dextran via a sulfhydryl group. Therefore, it was suggested that GSH might partially act as a cross linker since it has an amino group which also participates in the conjugation to the CNBr-activated dextran.

As shown in Table 1, the value of volume of distribution $(180 \mathrm{ml} / \mathrm{kg}$ body weight) was relatively higher than the total blood volume reported in mice $(77.8 \mathrm{ml} / \mathrm{kg}$ body weight). ${ }^{16)}$ Furthermore, $14.1 \%$ of FD-GSH was excreted totally in urine in spite of the higher molecular weight of $250 \mathrm{kD}$. The wider molecular weight distribution of FDGSH might accelerate the distribution into the interstitial fluid and the renal excretion; the lower molecular weight fraction was liable to be the recipient of both disposition processes.

Takakura et al. have studied in detail the effect of electrostatic charge of the macromolecular compound on its disposition after parenteral administration. ${ }^{15,17)}$ After i.v. injection of cationic dextran in mice, a rapid clearance from the circulation was seen with a high accumulation in the liver. In contrast, anionic dextran was retained in the blood circulation much longer, and hepatic uptake was relatively low. ${ }^{15)}$ In this study, comparatively higher hepatic distribution of FD-GSH (38\% of dose) was observed despite the negative charge of the conjugate. Furthermore, after distributing to the liver, FD-GSH continued to accumulate in the organ for a long period; the hepatic mean residence time was $12 \mathrm{~d}$ (Table 1).

The thiocarbamoyl linkage between fluorescein and dextrans is known to be perfectly stable under in vitro and in vivo conditions. ${ }^{18)}$ Size exclusion chromatography and ultrafiltration experiments demonstrated that no free fluorescein was detectable in plasma or hepatic homogenate after incubation of FD-GSH over a $120 \mathrm{~h}$ period (data not shown). Furthermore, although the FITC-labeled dextran was degraded appreciably to smaller oligosaccharides by incubation with a trace amount of dextranase, FD-GSH was not susceptible to the enzyme catalyzed hydrolysis due to the delivertization with $\mathrm{CNBr}$ (Kaneo Y, unpublished data). High performance size exclusion chromatography experiments indicated that FDGSH accumulated in the liver over a long period with the molecular size retained almost intact, but lacking the 
smaller molecular fractions due to the renal filtration. FD-GSH was also found to be secreted in the bile as it was in the initial stage of excretion (data not shown).

As shown in Fig. 1, the hepatic distribution of FD-GSH reached a maximum level $6-8 \mathrm{~h}$ after injection. At least $80 \%$ of the conjugated GSH was attached to dextran via sulfhydryl groups, and the conjugate liberated GSH at a half-life of $1.6 \mathrm{~h} .^{5)}$ Therefore, if either the slower liberation of GSH or the rapid hepatic uptake of the conjugate is attained, a further effective hepatic delivery system of GSH could be established. On the basis of these findings, a modification of the molecular design of the conjugate is now being undertaken.

\section{REFERENCES}

1) Meister A., Anderson M. E., Ann. Rev. Biochem., 52, 711-760 (1983).

2) Hahn R., Wendel A., Flohe L., Biochim. Biophys. Acta, 539, $324-337$ (1978).

3) Griffith O.W., Meister A., Proc. Natl. Acad. Sci. U.S.A., 76, 5606-5610 (1979).

4) Wendel A., Jaeschke H., Gloger M., Biochem. Pharmacol., 31, 3601-3605 (1982).
5) Kaneo Y., Fujihara Y., Tanaka T., Ogawa K., Fujita K., Iguchi S., Int. J. Pharm., 57, 263-272 (1989).

6) Kaneo Y., Tanaka T., Fujihara Y., Mori H., Iguchi S., Int. J. Pharm., 44, 265-267 (1988).

7) Kaneo Y., Fujihara Y., Tanaka T., Kozawa Y., Mori H., Iguchi S., Pharm. Res., 6, 1025-1031 (1989).

8) Kaneo Y., Fujihara Y., Tanaka T., Kozawa Y., Mori H., Iguchi S., Chem. Pharm. Bull., 37, 218-220 (1989).

9) Molteni L., "Drug Carriers in Biology and Medicine," ed. by Gregoriadis G., Academic Press, London, 1979, pp. 107-125.

10) Larsen C., Adv. Drug Delivery Rev., 3, 103-154 (1989).

11) Kaneo Y., Ogawa K., Tanaka T., Fujihara Y., Iguchi S., Biol. Pharm. Bull., 17, 1379-1384 (1994).

12) Belder A.N.d., Granath K., Carbohydr. Res., 30, 375-378 (1973).

13) Axen R., Ernback S., Eur. J. Biochem., 18, 351-360 (1971).

14) Ellman G.L., Arch. Biochem. Biophys., 82, $70-77$ (1959).

15) Takakura Y., Fujita T., Hashida M., Sezaki H., Pharm. Res., 7, 339-346 (1990).

16) Tanimoto Y., "Biological Reference Data Book on Experimental Animals," ed. by Tajima Y., Softscience Co., Tokyo, 1989, pp. 95-149.

17) Takakura Y., Takagi A., Hashida M., Sezaki H., Pharm. Res., 4, 293-300 (1987).

18) Schroder U., Arfors K.E., Tangen O., Microvasc. Res., 11, 33-39 (1976). 